\title{
Building sustainable creativity: a conceptual framework
}

\author{
P. Carmona Marques ${ }^{1}$
}

\begin{abstract}
:
Climate change, limited energy resources and population growth raise questions about sustainability and decisions for future generations. There is a need to contribute to a more sustainable world. This can be achieved with the use of creativity in, for example, product lifecycle management. Built on the literature about creativity and sustainability, a conceptual framework of sustainable creativity is proposed on the integration of the fields. The proposed framework is an attempt to the creation of sustainable concepts and includes the domains of "decomposition" and "integration" where the problem-, idea-, and concept-space are built on. Feedback loops are analysed and discussed as an important part of any radical/incremental product/service development within lifecycle management activities.
\end{abstract}

Keywords: sustainability, creativity, product lifecycle management (PLM)

\section{Introduction}

The world today faces environmental challenges, confronting the need to promote political and economical development for a better life (Alkire, 2002). Lifecycle Management (LCM) and Assessment (LCA) are perhaps leading areas of work where research and development activities are continually broadening (Hunkeler et al., 2004; Stark, 2004). This trend is consistent with the "lifecycle thinking" holistic approach (UNEP, 2012), where in author's view creativity can play a central role intended for sustainability. Since models that explain creativity in the field of sustainability are absent (Lozano, 2014), the focus is placed on the exploration of the field. Thus, the main goal of this paper is to propose of a conceptual framework of sustainable creativity.

\section{Basics of creativity and innovation toward sustainability}

\subsection{Knowledge creativity}

The "knowledge economy" (Drucker, 1996) is being replaced by the creativity economy (Gurteen, 1998). The new core competence is creativity. It is about creativity, imagination, insight and above all, innovation - the knowledge is commoditized. In fact, the new forms of innovation driving creativity economy forward are based on an intimate understanding of consumer culture, i.e., the ability to determine what people want even before they can articulate it (Kelley and Littman, 2001; Gmelin and Seuring, 2014).

\subsection{Defining creativity}

The literature about creativity introduces several definitions of the concept such as the ones proposed by Amabile (1996), Csikszentmihalyi (1999), Sternberg and Lubart 
(1999), and Weisberg (2006) among others recognized authors, generally from the field of cognitive psychology and engineering design community (Cross, 2000; Linsey et al., 2008; Coley et al. 2007; Howard et al., 2008). In a simple way creativity can be seen as the ability to produce work or come up with ideas that are both novel and usable and as a response to a problem that is heuristic rather than algorithmic (Amabile, 1996). Moreover, as Csikszentmihalyi (1999) and Weisberg (2006) recongnizes most researchers consider creativity as a topic of great relevance for both the individual and society. For the individual, creativity is used to solve problems and for society, it can lead for example to inventions, new scientific discoveries and movements in art. In addition, an economic importance should not be neglected on creativity since it is the creation of innovative products and services, which in developed societies are the backbone of economic growth (Sternberg and Lubart, 1999).

A creative product is new if someone produces something not produced before (Sternberg and Lubart, 1999). However, two concepts of creativity should be separated: novelty for the individual and novelty for society (Weisberg 2006). Which is novel for an individual does not mean necessary to be novel for society. An example is when someone discovers something he/she believes to be new but it already exists. The creative thinking includes the thoughts that a person introduces in products that are novel for the person, this is an innovation. A creative person is someone who produces those products. Furthermore, creativity encompasses activities that allow people to produce creative products and can depend on motivation and personality traits (Amabile 1996). Besides, to a product being novel it should also have value in the sense it is important to decide if the product is creative or not (Sternberg and Lubart, 1999). Csikszentmihalyi (1999) presented an analyses of the concepts of novelty and value in discussing creativity. According to Csikszentmihalyi (1999), creativity should be seen from the point of view of three important components: 1) the individual, who makes a novel variation in a domain; 2) a domain, consisting in a set of practices and rules; and 3) a field, consisting of experts from a social organization of a domain. The author sustains that creativity should be used to describe a product that passes through these three components.

Amabile (1996) characterized the task to achieve product innovation as being heuristic rather than algorithmic. Amabile (1996) relies on personal skills that are relevant to the domain in which an individual is working, including his/her knowledge and technical abilities. Skills are based in natural abilities and acquire during formal and informal education and training. They also rely on "creativity-relevant skills" such as the case of heuristics. The author typically defined an algorithmic task when the path to the solution is straightforward; on the contrary, a heuristic task is when it does not have a clear path solution and for which algorithms must be developed.

\subsection{Innovation \& PLM}

In companies, a distinction between creativity and innovation is normally made (Amabile 1996). The term innovation is more frequently used, instead of the term creativity, to refer to the entire process by which new ideas are created and converted into original and useful products and/or services. On the other hand, creativity is recognized as a necessary building block to trigger new ideas, concepts and approaches 
to deal with existent or emergent problems, normally characterized by the efficient and aligned management of large amounts of creativity (DeGraff and Lawrence 2002) creativity and innovation have to be balanced to introduce value capture to the company. One can also sustain that creativity is the building block of all innovations at companies nowadays. There are different components that characterize the success of innovation, being the most important the importance of being first-to-market and the characterization of the entire cycle of innovation.

There are of course global innovation opportunities and this deal with creativity management, new product development (NPD) and of course Product lifecycle management (PLM). PLM refers to the process of managing the entire lifecycle and value chain of a product portfolio, from the raw material, through design and manufacturing, to recycling and/or disposal (Karniel and Reich, 2011). PLM deals with complexity regarding people, processes, and data, and the information of the product's life (Stark, 2005). Main phases of PLM are related to New Product Development (NPD) activities (Gmelin and Seuring, 2014). In fact, Design for Sustainability (DfS) (Crul and Diehl, 2007) aims to introduce social and environmental aspects into product, being most effective when its objectives are aligned to a business strategy. Further, it can be applied to product-service systems (Marques et al. 2013). A product's environmental profile (Brezet and van Hemel, 1997) comprises: 0) New concept development; 1) Selection of green materials; 2) manufacturing technology optimization; 3) Efficient distribution; 4) Reduction of environmental impacts; 5) Optimization of product life and end-of-life system.

As Kelley and Littman (2001) refer, it is important to build innovation as a capability. This can be made through:

- $\quad$ carefully observing the behaviour of the people who will be using a product or service;

- $\quad$ brainstorming with high-energy sessions focused on tangible results;

- $\quad$ prototyping ideas and designs at every step of the way;

- $\quad$ cross-pollinating to find solutions from other fields of knowledge; and

- $\quad$ building a "greenhouse" for innovation.

Of course these aspects of innovation are well glued by strong leadership, climate and environment to innovate, multidisciplinary teams, among other.

2.4 Lifecycle assessment (LCA)

Finally, life-cycle assessment (LCA) should be highlighted in this literature review. Thus, LCA is a method to assess the environmental impacts associated with a product's life stages, from cradle to grave (Valero and Valero, 2013). A product-service's life cycle includes all stages of PSS, from raw material to the disposal of the product at the end of its life. This includes extracting and processing (conception, manufacturing, distribution, use, re-use, maintenance, recycling, and final disposal). LCA is performed to deal with environmental decisions during NPD (Hertwich et al., 2000) and is related to ISO 14000 environmental management standards, which includes single-site to large multi-national companies, high-risk companies to low-risk service, organizations, manufacturing, process, and the service industries, including local governments, all industry sectors (public and private), original equipment, manufacturers and their suppliers. 


\section{Conceptualizing creativity with sustainability}

\subsection{Method}

A framework of creativity has been proposed by Marques et al. (2014). The framework was built from reviewed models, theories and methods regarding creativity in engineering design research (Tang and Gero, 2002; Hatchuel and Weil, 2003; Hsiao and Chou, 2004; Jin and Chulsip, 2006; Howard et al. 2008). Summarly, Tang and Gero's model (2002) discussed creativity in engineering design and recognized that "generation" - decomposition and "evaluation" - integration has two important phases with iteration between them. Hsiao and Chou (2004) proposed a model for designing new products presenting the "problem and solution spaces". Jin and Chuslip (2006) studied mental iteration in design thus introducing feedback loops as artificial intelligence (AI) authors' Lawler and Yazdani (1991) proposed earlier. Howard et al. (2008) presented a model that joined creative cognitive psychology to engineering design. The $\mathrm{C}-\mathrm{K}$ theory (Hatchuel and Weil, 2008) explicitly considers an iteration process between the "concept" and knowledge domains. Also, there is evidence of specialization and generalization loops thus pointing out iterative engineering design practices as suggested by Ware (2008). As so, an attempt to develop a framework for sustainable creativity is to be made in order to integrate last items with PLM practices, thus providing individuals and organizations with a lifecycle thinking approach.

\subsection{The conceptual framework}

As discussed, the conceptual framework articulates the one proposed by Marques et al. (2014) with PLM to be used for any product/service that incorporates sustainability principles as shown in Fig 1.

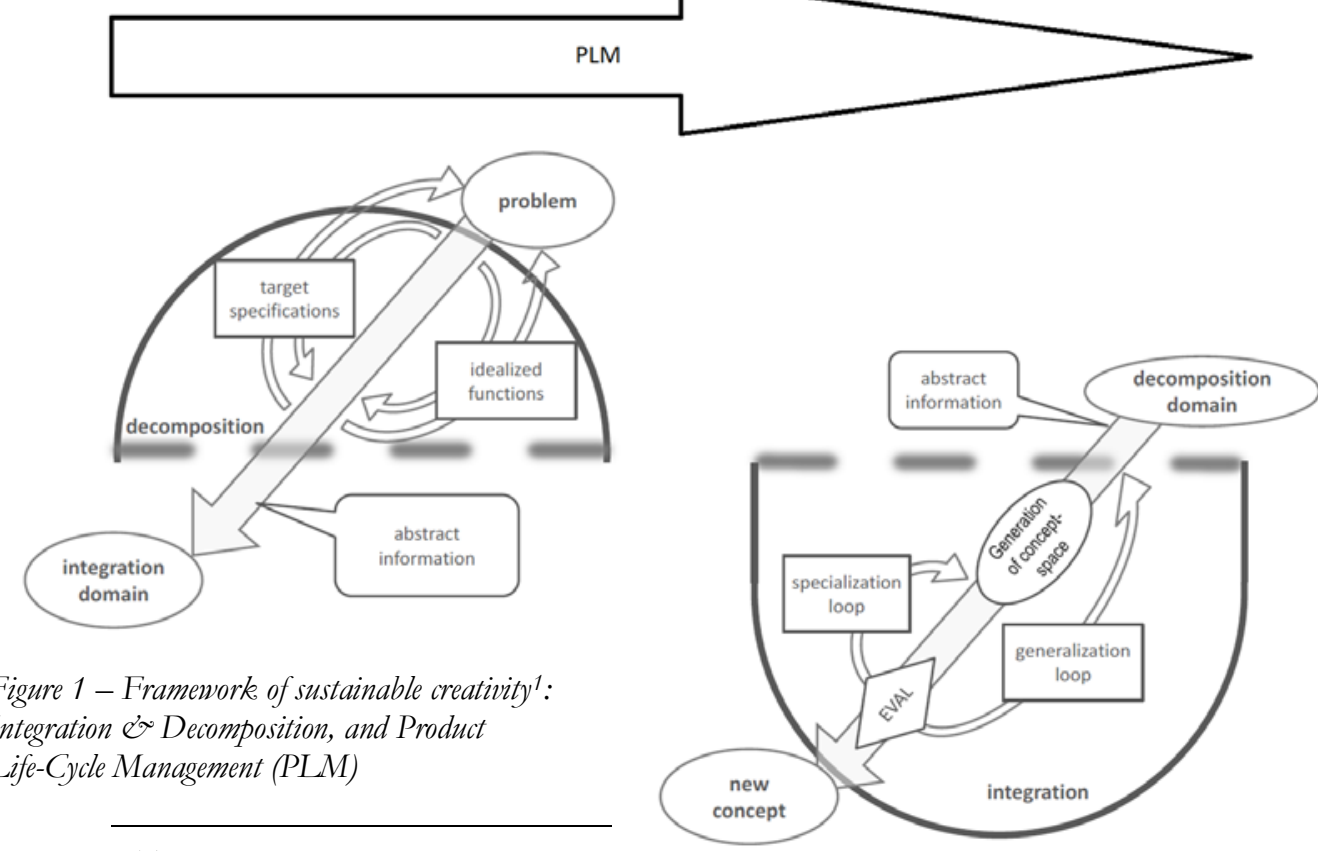

1 The term "sustainable creativity" is absent in the scientific literature through a search in Sciencedirect and Google Scholar. As so, this paper introduces now de term. 
The framework has two important fields derived from Marques et al. (2014): decomposition and integration. Within each field, there are "mechanisms", "heuristics", and "methods" that allow the creation of creative and sustainable concepts. The framework works with "technology push" and "market pull" principles thus incorporating problemspaces and idea-spaces. The intersection between a problem-space and an idea-space is called a concept-space. Decomposition breakdowns problems/ideas/concepts into abstract info of a sustainable design. In a PLM-engineering design problem this tactic to decomposition is similar to design for manufacturing issues and the optimization of the product life cycle. These items are then taken up by integration. Integration uses the former abstract info to come up with ideas/solutions to the problematic. The ideas formed during this process is the so called concept-space. The evaluation of the ideas/concepts can lead to three outcomes: (1) the concept meets the functions/specifications, therefore becoming a sustainable concept; (2), the concept shows partial fulfilment of functions/specifications so that the sustainable concept can be improved within a specialization loop of sustainability; (3), the concept is completely off target and something more radical needs to happen - the generalization loop of sustainability takes place as proposed by Marques et al. (2014).

\section{Further discussion of the framework of sustainable creativity}

Special attention to the gates (EVAL item in figure 1) in the framework that guide the specialization and generalization loops of sustainability is necessary for possible implications of the framework itself on product/service architecture. There is a need to identify a possible saturation in the specialization loop of sustainability, denoting that there are no other improvements at technological and/or business model levels, without changing the concept-space, or changing the architecture.

In terms of a product/service's nomenclature, one is talking about improvements and optimizations preserving a particular architecture, which is, achieving a better productservice within the same concept-space. Theoretically, when the potential for improvement is saturated, sustainable innovation on the product-service needs some kind of breakthrough, which means novel approaches, requiring a paradigm shift and/or the replacement of items in the concept-space.

More precisely, the generalization loop of sustainability could be a change of a conceptspace, but is also a change between different architectures. New product-services tend to have an integral architecture, however with the increasingly short life cycle, their architecture becomes more modular over time, reducing cost and increasing productservice variants (Baldwin and Clark, 2000). This leads to the hypotheses that the framework should work in dissimilar ways for new sustainable products-services and for incremental ones, thus interfering with architecture decisions. Theoretically, productservice systems' architecture should be interconnected with creativity

\section{Conclusion}

One has introduced and discussed a proposed framework of sustainable creativity. Up to now, the integration of the fields of creativity, innovation and 
sustainability have been achieved and an attempt to modulate it conceptually was performed. First of all, it is clear that the framework can be used during lifecycle management, if during for example a process of creative creation of a product or a service (either radical or incremental), PLM principles are taken into consideration. From the point view of theory this is not an easy task to achieve but there now attempts to do it and shift the paradigm to a cleaner production future. For example, the Aalto University ${ }^{2}$ in Finland, started in 2010 a master's degree in Creative Sustainability with the objective of creating "new sustainable solutions for human, urban, industrial and business environments".

Also, the framework presented and discussed so far might contribute to a future model of sustainable creativity if case studies are tested. In particular, one has to take into consideration how feedback loops are used according to the individual, the type of organization/companies, manufacturing process, industry sectors, suppliers/retailers (supply chain management) among others.

Another challenge, is the contribution that LCA could make to be integrated in the framework. For example, how shall one connect LCA general arguments to the specialization and generalization loops of sustainability presented so far?

Very recently, Paul Shrivastava $(2014)^{3}$ from Concordia University, Canada, as introduced a new theme for discussion - "paths for integrating creativity and sustainability" with a panoply of questions for future research, such as: How can creativity drive triple bottom-line initiatives during the short and long term? Is sustainable creativity possible? How do crises such as climate change related threats help to foster or hinder holistic integration of creativity within organizational strategy development and implementation? One hopes that the current paper helps in finding answers to this questions.

\section{References}

Alkire, S. 2002. Dimensions of Human Development. World Development. 30(2), 181-205

Amabile, T. 1996. Creativity in Context, Westview Press, Oxford

Baldwin, C., Clark, K., Design Rules, Vol.1: The Power of Modularity, MIT Press, Cambridge MA, 2000.

Brezet, H., van Hemel, C. 1997. ECODESIGN - A promising approach to sustainable production and consumption. UNEP.

Coley, F., Houseman, O., and Roy, R. 2007. An introduction to capturing and understanding the cognitive behavior of design engineers. Journal of Engineering Design, 18 (4), 311-325.

Cross, N. 2000. Engineering design methods - Strategies for product design (2 ed.). Chichester: Wiley.

Crul, M., Diehl, J.C. 2007. Design for Sustainability (D4S): A Practical Approach for Developing Economies, UNEP publication

Csikszentmihalyi, M. 1996. Creativity: Flow and the Psychology of Discovery and Invention, Harper Collins, New York

DeGraff, J., Lawrence, K. 2002. Creativity at Work, Developing the Right Practices to Make Innovation Happen, University of Michigan Business School Management Series, 2002.

Drucker, P. 1969. The Age of Discontinuity; Guidelines to Our Changing Society. New York: Harper and Row

Finkbeiner, M. 2012. From the 40s to the 70s - the future of LCA in the ISO 14000 family. Int. J. Life Cycle Assess. 18(1), 1-4

Gmelin, H., Seuring, S. 2014. Determinants of a sustainable new product development. J. Clean. Prod. 69, 1-9

\footnotetext{
2 http://acs.aalto.fi/

3 doi:10.1016/j.jclepro.2014.06.015
} 
Gurteen, D. 1998. Knowledge, Creativity and Innovation. J. of Knowledge Management 2 (1), 5-13

Hatchuel, A., and Weil, B. 2003. A new approach of innovative design: an introduction to C-K theory. International Conference on Engineering Design - ICED03. Stockholm.

Hertwich, E., Hammitt J., Pease, W. 2000. A theoretical foundation for life-cycle assessment recognizing the role of values in environmental decision making. J. Ind. Ecol. 4 (1), 13-28

Howard, T. J., Culley, S. J., and Dekoninck, E. 2008. Describing the creative design process by the integration of engineering design and cognitive psychology literature. Design Studies, 29 (2), 160180.

Hunkeler, D., Rebitzer, K., Schmidt, G., Jensen, W., Strandorf, A., Christiansen, H. 2004. Life Cycle Management. SETAC Press, Pensacola, FL

Hsiao, S. W., and Chou, J. R. 2004. A creativity-based design process for innovative product design. International Journal of Industrial Ergonomics, 34, 421-443.

Jin, Y., and Chusilp, P. 2006. Study of mental interaction in different design situations. Design Studies, 27, 25-55.

Karniel, A., Reich Y. 2011. Managing the Dynamics of New Product Development Processes: The New Product Lifecycle Management Paradigm, Springer

Kelley, T, and Kelley, J. 2001. The Art of Innovation: Lessons in Creativity from IDEO, America's Leading Design Firm, Profile Books, London

Lawler, R., and Yazdani, M. 1991. Artificial Intelligence and Education: Principles and case studies. Norwood, New Jersey: Ablex Publishing Corporation.

Linsey, J., Wood, K., and Markman, A. 2008. Modality and representation in analogy. Artificial Intelligence for Engineering Design, Analysis and Manufacturing, 22, 85-100.

Lozano, R. 2014. Creativity and Organizational Learning as Means to Foster Sustainability. Sust. Dev., 22, 205-216

Marques, P., Cunha, P., Valente, F., Leitão, A. 2013. A Methodology for Product-Service Systems Development. Proc. CIRP. 7, 371-376

Marques, P., Silva, A., Henrqiues, E., Magee, C. 2014. A descriptive framework of the design process from a dual cognitive-engineering perspective, Int J of Design Creativity and Innovation, 2 (3), 142-164

Stark, J. 2004. Product Lifecycle Management: 21st century Paradigm for Product Realisation, Springer

Sternberg, R., Lubart, T. 1999. The Concept of Creativity: Prospects and Paradigms, in: Sternberg, R. J. (Eds.), Handbook of Creativity. Cambridge University Press, pp. 3-15

Tang, H.-H., and Gero, J. S. 2002. A cognitive method to measure potential creativity in designing. In C. Bento, A. Cardoso, and G. Wiggins, Workshop 17 - Creative Systems: Approaches to Creativity in $\mathrm{AI}$ and Cognitive Science (pp. 47-54). Lyon: ECAI-02.

UNEP 2012. Greening the Economy through Life Cycle Thinking: Ten Years of the UNEP/SETAC Life Cycle Initiative, United Nations Environment Programme

Valero, A., Valero, A., 2013. From grave to cradle. J. Ind. Ecol. 17 (1), 43-52.

Ware, C. 2008. Visual Thinking for Design. Burlington, MA: Elsevier Inc.

Weisberg, R. 2006. Creativity: understanding innovation in problem solving, science, invention, and the arts, John Wiley, Hoboken, New Jersey 